\title{
ЭЛЕКТРОЛИТНЫЕ НАРУШЕНИЯ У ГОСПИТАЛИЗИРОВАННЫХ ПАЦИЕНТОВ С COVID-19
}

\author{
Абилов З.В., Кононыхина А.П., Сардаева Д.Г., Катамадзе Н.Н., Пигарова Е.А., Дзеранова Л.К., Марова Е. И., \\ Реброва О.Ю., Мельниченко Г.А., Мокрышева Н.Г. \\ ФГБУ «НМИЦ эндокринологии» Минздрава России
}

ЦЕЛЬ: изучить распространенность электролитных нарушений (гипонатриемия, гипокалиемия) среди пациентов с COVID-19 и оценить их возможную связь с тяжестью заболевания и исходами.

МАТЕРИАЛЫ И МЕТОДЫ: были изУчены медицинские карты 153 пациентов, госпитализированных для стационарного лечения инфекции COVID-19 с мая по июнь 2020 года. В исследуемую группу вошли 75 мужчин (49\%) и 78 женщин (51\%), средний возраст 60 лет [Q1 47; Q3 73], ИМТ 28,7 кг/м² [25,0; 32,9]. У всех пациентов была диагностирована пневмония, вызванная SARS-CoV-2 со средним процентом поражения легких 28,5\% [15,3; 44,7]. Медиана SpO2 составила 94\% [92; 97], а средний балл NEWS составил 3 [2; 6]. Было зафиксировано 10 смертельных случаев. 14 пациентов при поступлении получали терапию диуретиками.

РЕзУЛЬтАТЫ: при поступлении медиана натриемии составила 137 ммоль/л [135; 139], гипонатриемия ( $\mathrm{Na}<135$ ммоль/л) выявлялась у 25\% (95\% ДИ 18-32\%), выраженная гипонатриемия ( $\mathrm{Na}<130$ ммоль/л) у 4,6\% (95\% ДИ 2-9\%), гипернатриемия (Na>145 ммоль/л) у 0,6\% (95\% ДИ 0-4\%) пациентов. Средний уровень калия составлял 3,8 ммоль/л [3,5; 4.2], гипокалиемия (К<3,5 ммоль/л) выявлялась у 17,6\% (95\% ДИ 12-25\%), гиперкалиемия (К>5,1 ммоль/л) у 2,6\% (95\% ДИ 1-7\%) пациентов. Сахарный диабет (СД) наблюдался у 15\% пациентов и ассоциировался с более низким уровнем натрия 135 ммоль/л [132; 136] против 137 ммоль/л [135; 139] у пациентов без СД ( $p=0,003$, критерий Манна-Уитни), но не с уровнем калия. Уровни Na и K при поступлении не были связаны с применением диуретиков пациентами. Выявлен тренд к связи уровня натрия с температурой тела $(R=-0,20, p=0,01), S p O 2(R=0,20, p=0,02)$, оценкой по шкале NEWS $(R=-0,20, p=0,02)$, C-реактивным белком (СРБ; $R=-0,21, p=0,01)$, протромбиновым временем $(R=-0,29$, $\mathrm{p}=0,0005)$, днями госпитализации $(\mathrm{R}=-0,22, \mathrm{p}=0,009)$ и днями респираторной поддержки $(\mathrm{R}=-0,22, \mathrm{p}=0,006)$, но не с возрастом, ИМТ, \% поврежденной легочной ткани, систолическим или диастолическим артериальным давлением или уровнем D-димера. Также выявлен тренд к связи уровня калия с систолическим артериальным давлением ( $R=-0,17, p=0,04), C P Б(R=-0,22, p=0,007)$, но не с другими ранее упомянутыми параметрами для натрия.

ВЫВОдЫ: настоящее исследование демонстрирует высокую распространенность нарушения гомеостаза натрия и калия среди госпитализированных пациентов и возможное влияние электролитных нарушений на тяжесть течения COVID-19. Таким образом, необходимо оценивать уровень натрия и калия при госпитализации у пациентов с COVID-19. 